\title{
Early Warning Indicators of Strategic Risk in Togolese Commercial Banks: An AHP Model Approach
}

\author{
Kolani pamane ${ }^{1}$, Xie Kefan ${ }^{2}$, Koami Mawuienam Amadotor ${ }^{3}$ \\ ${ }^{I}$ School of Management, Wuhan University of Technology, China \\ ${ }^{2}$ School of International Education, Wuhan University of Technology, China \\ ${ }^{3}$ West African Economic and Monetary Union, Ouagadougou, Burkina Faso
}

\begin{abstract}
Strategic risk has become a crucial area of interest of most banking sector's practitioner, and its management a pre-requisites for a sustain growth and business competitiveness of financial institutions. This research focuses on the assessment of strategic risk within Togolese banks, in order to elaborate an early warnings model that provides signals for strategic deterioration and vulnerabilities. The research involved eleven banks and is based on the AHP model assessment of strategic factors in banks. The results suggest that Togolese banks should focus on three main factors which provide the strongest signal of strategic deterioration of the banking business. More specifically, strategic planning process and the resistance to culture change are revealed to be the factors that provide the strongest signal of a strategic vulnerability, with more emphasis on the decision making method, the organizational culture, the strategic planning, change in shareholder's behavior, political risk and the level of risk tolerance. The study finally established that strategic risk management remain a relatively new approach which is not yet a part of the organizational culture of most of the banks in Togo, and that the overall knowledge on strategic its management process has been proven to be literally weak.
\end{abstract}

Key Words: Early Warning System, Banking sector, Risk Management, Strategic Risk, Togolese Banks,

\subsection{Statement of the problem and objectives}

\section{Introduction}

The financial liberalization of the 80 's and 90 's was follow in many countries by the bankruptcy of banks (see Lambert, The Cacheux Mahuet [1997]) ${ }^{[1]}$. Costs engaged by banking crises for the whole society have led to think of a re-regulation of this sector and to reflect on the extent of risk taken by financial intermediaries. If internal control and market discipline are encouraged to engage the bank on a sound risk management, the place in this area by organizations banking supervision and a well defined risk management tools and procedures remains very essential. The supervision role consists on collecting data from the financial institutions and banks database in order to evaluate their financial conditions. To facilitate this analysis which is essential to the detection of the institutions and their main sectors at risk, the bank supervisory agencies have developed some warning procedures to alert (early warning system '). These procedures are designed to quickly identify institutions or banks that financial situation seems at risk and focus their attention on them. Recent studies trace the evolution of these warning systems either in the U.S. (Reidhill and O'Keefe [1997] and Cole, Cole, and Gunther [1995] ${ }^{[2]}$ or more widely in countries members of the G10 (Sahajwala, Van den Bergh [2000] and Logan [2000]). Given these studies, two generations of warning system coexist today when considering the evaluations differences of the banks fragility or weakness. The first generation of early warning system seeks to give a score (or make classification), reflecting the fragile state of each bank from the analysis of different financial ratios, while The second generation of early warning system uses statistical models to estimate the probability of failure of each bank at a given time horizon. more recently with the uprising of the strategic risk management framework, the first generation of the early warning models is being updating to fit the challenge of risk factors classification and provide early indicators of strategic soundness or deterioration.

Nowadays the risk management strategies mainly takes into account and incorporate the early warning systems concept in their procedures, it becomes relevant and practical for the determination of the different sectors at risk within the banks and financial institutions and to provide earlier indicators of a bank vulnerability or distress. in addition, facing today's increasingly frequent risk factors of commercial banks, the need to develop practical risks control procedures and relevant measures becomes primordial, thus the establishment of Early-warning systems of key risks would play a very important role in the future risk management. Considering the new trend in the banking system characterized by Innovation, deregulation and globalization in banking, banking business became more complex and potentially riskier. This has presented new challenges to bank managers and supervisors with respect to the structuring of their ongoing risk management and supervision. In response, supervisors have found necessary to develop new methods and processes for monitoring and assessing banks on an ongoing basis. Particular attention is being paid in this regard to improving the quality of bank 
examinations and to the development of systems that can assist supervisors and managers in identifying changes, particularly deterioration, in banks' financial and non financial condition as early as possible. Amongst the various new initiatives that have been taken or are being taken in this respect are the development of more formal, structured and quantified assessments not only of the financial performance of banks but also of the underlying risk profile and risk management capabilities of commercial banks. Collectively these various new approaches can be termed "risk management and early warning systems".

Risk management and especially strategic risk management is therefore regarded today as a key factor in competitiveness in the banking environment that allows banks to better identify, measure, analyze and control the risks they face. Togolese commercial banks have not remained on the sidelines of this mismanagement and the need to adopt new approaches for risk management. Our study is therefore devoted to this achievement and is aim more precisely to investigate on the strategic risk assessment and practices within Togolese commercial banks in order to develop some early warning indicators of the banks vulnerabilities and distress at the strategic level.

\section{Aim and Significance}

This decade has known the advent of many financial crises and banking business malfunctioning that affected key sectors of several countries including Togo. The impact of these crises on the economies of Western and African countries is no longer to be demonstrated both in financial markets and in the banking sector. Faced with the upsurge of crises, financial institutions have adopted adequate measures to protect or minimize the impact of these crises and business failure. In the banking sector, measures such as the development of early warning systems and the integration of risk management departments in banks have become more indispensable. Risk management is therefore regarded today as a key factor in competitiveness in the banking environment that allows banks to better identify, measure, analyze and control the risks they face. It is possible that within a bank's risks are managed individually at each department or service, but given the correlations between different risks that could cause either the minimization or maximization of those risks, it is found essential to establish an overall risk management plan to be an overview of all risks, and coordinate all activities and processes related to managing these risks. This fact concerning the position of the banks toward risk management and the establishment of an effective business strategy is increasingly felt and considered primordial by the regulatory actors of the banking system in Africa. It thus becomes evident that banks in Africa and particularly in Togo are trying to integrate the dynamics of effective management of risk and prudential warning system in their daily business. But this remains a very difficult task to accomplish due to the specific appearance of African banking environment which makes difficult the adoption of a Western model. in this context it seems obvious and necessarily adequate to conduct studies on the characteristics of the banking environment in Africa, the risk management procedures in commercial banks, and propose measures for more adequate and appropriate system for African Banks in general and Togolese one in particular.

Our study is therefore devoted to this achievement and is aim more precisely to investigate on the assessment of strategic risk within Togolese commercial banks in order to develop some warning indicators for the earlier detection of vulnerabilities and threats at the strategic level.

* This study is of great significance for banking regulatory actors, board of director of commercial banks and the banks themselves, stakeholders of the banks, but also for the literature.

* Through in-depth analysis and review of different approaches and methods of risk management, regulatory bodies of the banking system will be able to formulate new procedures and risk control strategy more adequate and adapted to the Togolese banking environment.

* This study reveals to the concern board how important and necessary it is to effectively and efficiently incorporate risk management in the process of strategy setting and decision making.

* The study will help banks managers in their management process to ensure that risk remains within the boundaries established by the board and that business lines comply with risk parameters and prudential limits established by the Board.

Beside the reasons mentioned above, this research therefore reveals a great significance insofar as it will contributes to the latter nonexistent literature about the strategic risk assessment in African commercial banks. This will also generate a renewed interest on the Strategic Risk Management and its importance in the definition of an effective strategy for commercial banks as a whole and especially that of Togo.

\section{Review of the literature about Strategic Risk and EWS in Banks}

In terms of banking and financial institutions, many risks have to be considered, arising from the financial to the non - financial risks. As mention earlier, the most reviewed risks in the banking sector remain the market risk (interest rate risk), the credit risk and the operational risk. In this perspective, several researchers have focused their work on how to properly manage those risks and especially how to design effective Early 
Warning Systems to predict and control them. The BASEL Accord ${ }^{[4]}$ also focus on designing the principle and procedure on how to manage the 3 most important risks facing the banking institution namely market, credit and operational risk without including the strategic risk which seems more and more neglected. This lack of emphasis on that specific risk lead to a very poor literature relating to strategic risk management and especially on an Early Warning System of strategic risk for commercial banks.

The extent of the banking risks and the difficulty of anticipating them highlighted the need to improve monitoring capabilities both nationally and internationally. These problems have led to the rapid implementation of a set of future troubles or banks failure occurrence indicators, built on the basis of statistical studies of previous banking crises. Many national and international financial institutions have developed a series of measures designed to prevent distress related to common or idiosyncratic shocks. These models which attempt to contain the local or systemic risk have changed dramatically in recent years (Gaytan and Johnson, 2002) ${ }^{[5]}$. The changing environment of banks and the banking system requires an adaptation of supervisors and regulatory authorities and their methods of risk monitoring. It gives the bank supervision process a key role in the stability of banking systems. To assess the vulnerability of banks and identify the most vulnerable institutions to risk oversight bodies have a wide range of instruments ranging from the "on-site," monitoring to an "off-site" monitoring. In terms of strategic risk management, focus has been given to the "Bank Failure and Institutional Early Warning Systems". It is based on the integration of institutional factors as key variable in explaining the failure of a bank. Consideration of institutional factors improves the predictive power of the model. To take into account the role of institutional factors, this new generation of early warning models proceeds in a two-equation modeling to separate the internal risk factors that affect the solvency of the bank from the external factors (regulatory and institutional). Thomson (1992) makes a distinction between insolvency and bankruptcy which concern an arbitrary legal and regulatory decision. He proposes to model the decision to close the bank by the regulator as an option to buy (call). The proposed model consists of two equations: the first represents the net value of the bank (bank credit) and the second represents the closure of the establishment (that is to say, the propensity of the regulator to intervene in a bank difficulty). The traditional approach including institutional factors to assess financial vulnerabilities of individual banks is closely related to supervisors of the banking system and rating agencies work. the on -site examination of the supervisory agencies has a key role to play in this approach in so far that it helps to summarize the indicators of bank strength by some key variables. As we know the CAMEL rating system remain the most known in this field and Frequently, by this method, the score of individual performance for each bank is computed relative to all the other institutions, generating a unique rating index.

Empirical study related to early warning systems for commercial banks mostly interrogate about the ability of these warning systems to identify, before the onset of crises, institutions which will encounter difficulties. Left apart some few researchers among whose (Laviola et alli [1997] for Italy or Logan [2001] for England), literature on the prediction of bank failures and risk management (in addition to Article pioneer Sinkey [1975] including Thomson ${ }^{[6]}$ [1991], Whalen [1991], Cole and Gunther [1998], Estrella, Park and Peristiani [2000] ${ }^{[7]}$ and Kolari and ali.[2000]) primarily focus on the American case. This fact is partly explained by the low frequency of bank failures in other countries and especially in African countries which doesn't help to validate the facts of such systems.

Amran, et al. (2009) ${ }^{[8]}$, explored the availability of risk disclosures in the annual reports of Malaysian companies. The study was aimed to empirically test the characteristics of the sampled companies. The level of risk faced by these companies with the disclosure made was also assessed and compared. The findings of the research revealed that the strategic risk came on the top. The extent of risk disclosure was also found to be influenced by the nature of industry. In the same logic Hassan, A. (2009) ${ }^{[9]}$, research on the "Risk Management Practices of Islamic Banks of Brunei Darussalam" and assess the degree to which the Islamic banks in Brunei Darussalam implemented risk management practices and carried them out thoroughly by using different techniques to deal with different types of risks. He found that, like the conventional banking system, Islamic banking was also subjected to a variety of risks due to the unique range of offered products in addition to conventional products. The findings also reveal that there was a well understanding of what is risk and risk management by the staff working in the Islamic Banks of Brunei Darussalam. The major risks faced by those banks were Foreign exchange risk, credit risk and operating risk. The results of the regression model show that risk Identification, Risk Assessment and Analysis, were the most influencing variables; and the Islamic banks in Brunei needed to give more attention to those variables to make their Risk Management Practices more effective. Al-Tamimi and Al- Mazrooei (2007) ${ }^{[10]}$ focused on a comparative study of Bank's Risk Management of UAE National and Foreign Banks. The findings pointed out that the three most important types of risks facing the UAE commercial banks were foreign exchange risk, credit risk and operating risk. They also found that the UAE banks were somewhat efficient in managing risk; however the variables such as risk identification, assessment and analysis proved to be more influencing in risk management process. Finally, the results 
indicated that there was a significant difference between the UAE National and Foreign banks in practicing risk assessment and analysis, and in risk monitoring and controlling.

Li Peng proposed an early warning system to manage Bank reputational risk. As a non financial risk, he based the EWS on six explanatory factors namely emotional appeal, products and services, vision and leadership, workplace environment, financial performance and social responsibility. He suggests that reputational risk should be integrated in the whole risk management process in order to build a joint working group and Monitor the reputation by the early-warning system as well as improving transparency within the bank.

As it can be seen, the literature is relatively poor concerning a strategic risk early warning models which in fact was considered for many years as not important compare to the other risks such as the credit and the operational risk until the recent 2008 financial crisis. This crisis led the banking practitioners and regulators to acknowledge the vulnerability of the existing systems of risk management and brought their attention to address many of the significant risk management weaknesses and malfunctioning especially towards strategic risk which was pointed out to be one of the main causes of this crisis hence the increasing importance given to its management within banks during the last few years.

\subsection{The Implementation of the Early Warning System}

\section{Methodology}

Every financial Institution or Bank is expected to develop an appropriate framework for managing strategic risk, regardless of its size or complexity, and Togolese banks are not spared of it. As such, any bank willing to maintain a long term profitability should focus on developing a risk management framework that fits it risk profile and level of sophistication, and ensure that it main risks are consistently and comprehensively identified, assessed, monitored, controlled and reported at a strategic level. The methodology we intend to use for the early warning system implementation in BKC-Togo banks will illustrate the key elements of strategic risk management that the Banks are expecting to face and provide relevant early deterioration signal for the main indicators of Strategic risks as well as a suitable risk management guidance. we use for this purpose the AHP model. this model is a combination of a qualitative assess of the main factors characterizing strategic risk in banks and a quantitative measure of the vulnerability of the bank through some main indicators of the bank's distress.

\subsection{The Analytical Hierarchical Process (AHP)}

AHP is a multi-attribute decision-making model proposed by Saaty. Given its advantages of integral structure, simple theory, and ease-of-operation, this method is often used in strategic decision-making when addressing events of uncertainty and under various evaluation criteria. For the decision-makers, the hierarchical structure contributes to provide a better understanding, however, it is often necessary to evaluate alternatives based on other criterion, in order to determine priorities and determine an optimal plan. AHP contains an inherit analytical framework, wherein complex and nonstructural situations are divided into hierarchical elements. Then, the relative significance of every element is scored subjectively by numerical value, and the level of priority is obtained from these values as the factor weights. Another essential area of use of the AHP model is in the assessment of risk and prioritization of risk factors the can possibly harm an institution business and provide early warning signal for strategic risk assessment based on a risk index . The Analytic Hierarchy Process offers an interesting and useful way of developing national strategic risk assessments. The basis of the approach is 'pair -wise' comparison of elements in a matrix. The elements — such as issues, risks or threats — are compared or assessed by experts on a pair-wise basis in terms of importance, preference or perceived likelihood, depending on the purpose of the model being developed. in our case, the model will be designed in terms of importance and likelihood of strategic risk factors occurrence. The technique uses a numerical scale going from 1 to 9 and the inverse of these values, i.e., $1 / 2$ to $1 / 9$, to assess each comparison. when the two elements being compared are deemed to be of equal importance or probability, they are given a pair-wise score of 1 . If one element under consideration was considered to be far more important than another, then the value 9 could be assigned. Other values between these extremes reflect comparison possibilities that are greater than equality but less than extreme. Those values are 2, 4, 6 and 8.

This methodology require to gather data from a set of sample respondents which mostly are experts and professionals involved in risk management, through the administration of a questionnaire based on a pairedwise comparison. The central aim of all of this method is not only to identify strategic risks, but also to rate them in importance and likelihood of occurrence. Therefore, rational and informed policy decisions can be made concerning the allocation of resources, and mostly to prevent or moderate either the impact or probability of occurrence of a given strategic risk.

For the purpose of our study, Super Decision software is used to perform all the calculations. 
Super Decisions software implements the Analytic Hierarchy Process (AHP) and Analytic Network Process (ANP) for decision making with dependence and feedback, a mathematical theory for decision making developed by Thomas L. Saaty. The software for the decision making with dependence and feedback was developed by William Adams in 1999-2003. He and his team have developed software which can undergo AHP and ANP and is known as Super Decision from Creative Decisions Foundation, 4922. Adams and Saaty mentions that ANP is an extension of his Analytic Hierarchy Process (AHP) for decision making which involves breaking down a problem into its decision elements, arranging them in a hierarchical structure, making judgments on the relative importance of pairs of elements and synthesizing the results. With the AHP the process is top-down. the software is a simple easy-to-use package for constructing decision models with dependence and feedback and computing results using the super matrices of the Analytic Network Process. As mentioned earlier, the AHP process requires going through different phases of method to achieve the final result. Structuring the problem and building the AHP model.

Collecting the data from expert interview

Pair-wise comparison of each factor

Calculation of consistency index to rank Optimization requirement of each risk

Determination of the Risk indexes

In Analytical Hierarchy Process for risk assessment the decision maker starts by laying out the overall hierarchy of the decision or the different indicators characterizing a typical risk. This hierarchy reveals the factors to be considered as well as the various alternatives describing the risk. Here both qualitative and quantitative criteria can be compared using a number of pair wise comparisons, which result in the determination of factor weights.

The conventional AHP process consists of the following steps.

Step 1

A problem under complicated situations is decomposed to a hierarchy structure. However, the top level consists of one element, an overall goal of the problem. The elements of lower levels are determined subjectively by the decision maker according to the relationships of each element with the elements of the immediately above level. Finally alternatives are listed on the lowest level.

Step 2

The elements of intermediate levels are weighted. Namely, each element on a level is evaluated about the elements, i.e. criteria, on the immediately above level to acquire relative weights (wi) of the elements on the same level. the weights are obtain trough a mathematical process in a Paired comparison matrix established using the evaluation criteria and alternatives, as shown in the equation 1 and 2.

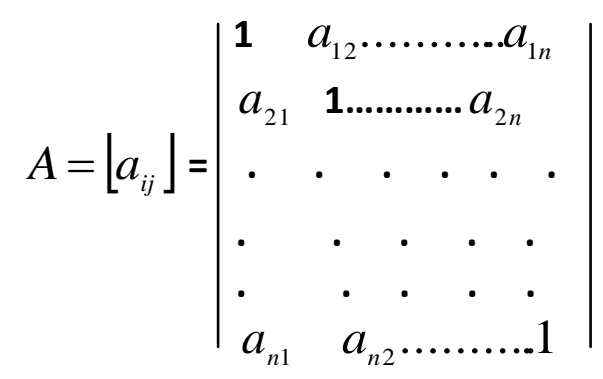

Where $a_{i j}=w_{i} / w_{j} \quad a_{j i}=1 / a_{i j} \quad \mathrm{i}, \mathrm{j}=1,2,3, \ldots \ldots \ldots \ldots \ldots \mathrm{n}$

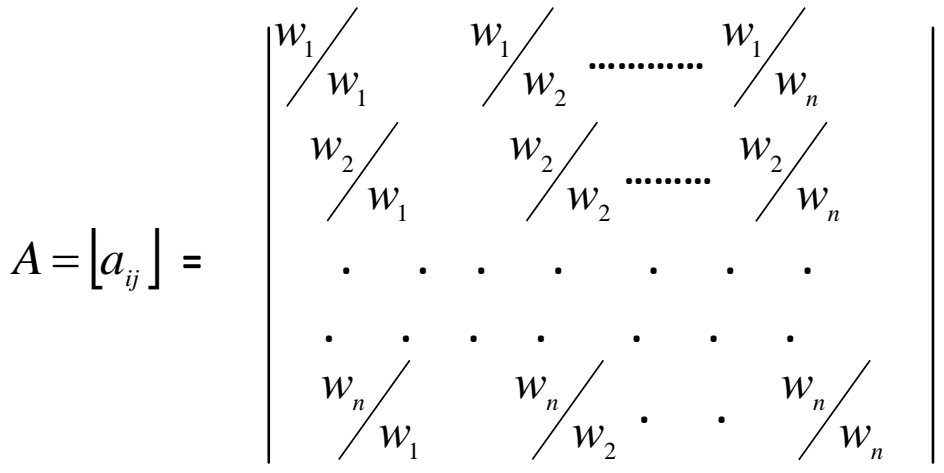


Where, $w_{i}$ is the weight of $\mathrm{i}$-criterion, $w_{j}$ is the weight of $\mathrm{j}$ criterion.

Matrix A is repeated for each criterion, then again for each sub-criterion, and for the objective of the problem. The dimension of matrix $\mathrm{A}$ is $\mathrm{n} \times \mathrm{n}$ and corresponds to the total of the productive alternatives being compared. Some properties of matrix A are: a) It is reciprocal, that is, aij $=1 /$ aij for all $i, j=1,2, \ldots, n$; b) From the former, we also have aii $=1$ for all $\mathrm{i}=1,2, \ldots ., \mathrm{n}$; $\mathrm{c}$ ) If all judgments are perfectly consistent, then $a_{i j}=a_{i k} a_{k j}$. If (c) is satisfied, then the elements of matrix A do not contain errors of judgment, therefore $a_{i k} a_{k j}=w_{i} w_{k} / w_{k} w_{j}=w_{i} / w_{j}=a_{i j}$ for all $\mathrm{i}, \mathrm{j}, \mathrm{k}=1,2, \ldots ., \mathrm{n}$ must be satisfied.

In the case that there are inconsistencies in the judgments, the AHP methodology considers the eigenvector method to estimate weightings which allows correcting the inconsistency by calculating $\mathrm{w}$ as the main correct eigenvector of matrix $\mathrm{A}$ as we can see in equation 4 .

$A_{w}=\lambda_{\max } w$

Step 3

The weight of the entire hierarchy is acquired using the weights of the elements on each level. According to the weight, priority of each alternative for the overall objective is acquired.

After the estimation of the paired comparison matrix, we will compute the consistency ratio which Judge the consistency of the paired matrix. The consistency ratio is obtained from consistency index (CI) and random index $(\mathrm{RI})$ and the formula is set as follow:

$$
C I=\frac{\lambda_{\max }-n}{n-1} \quad \text { (5) } \quad C R=\frac{C I}{R I}
$$

Where, $\lambda_{\max }$ is the largest eigenvalue, $\mathrm{n}$ is the number of evaluation criteria, $\mathrm{RI}$ is the random index of evaluation matrix.

we then Compute the normalized comparison value of risk factor $i$ to factor $j$ The normalized value of each risk factor is found by calculating the sum of the ith row (or column) and dividing each entry by related summation $(\mathrm{Si})$. The calculated matrix can be denoted by:

$$
\begin{aligned}
& R^{h}=\left[\left(R_{i j}\right)_{n x n}\right]^{h} \quad \mathrm{i}, \mathrm{j}=1 \ldots \ldots \ldots \ldots \ldots \ldots \mathrm{n} \quad \mathrm{h}=1 \ldots \ldots \ldots \ldots . . \mathrm{n} \text { where } \\
& r_{i j}=a_{i j} /_{s_{j}} \text { and } s_{j}=\sum_{i=1}^{m} a_{i j}
\end{aligned}
$$

Step 4

The relative weights of criteria will be then calculated Based on the established paired comparison matrix, calculate the eigenvector of every criterion according to the factors in the matrix, and obtain the relative weight.

$$
P W_{i j}=\frac{a_{i j}}{\sum_{i=1}^{I} a_{i j}}
$$

$$
I W_{i}=\frac{\sum_{j=1}^{J} P W_{i j}}{J}
$$

Where

$P W_{i j}$ is the partial vector of criteria (equal to eigenvector/total value of individual plan's characteristics);

Relative weight $I W_{i}$ (equal to partial vector of criteria/number)

\subsection{Strategic Risk Assessment AHP model \\ 4.3.1 Method and Materials}

The study was applied to a set of qualified expert in risk management within banking sector. The respondents were asked to provide their expertise regarding several strategic risks factors and sub- factors in terms of their significance of harming an institution at the strategic level, and in terms of likelihood of occurrence. 
For the purposes of illustrating our strategic risk AHP model, we identified a list of thirty -eight (38) strategic risk factors for commercial banks - issues, risks or threats which one might reasonably expect to see arising from a global strategic risk assessment. The factors are selected based on the various bodies of literature review about the source and the causes of strategic risk in banks and in consultation with expert opinions from managers, senior and professionals in strategic risk management. the factors are then divided into Criteria and sub-criteria characterizing the strategic risk in banks as illustrated in the table 1.

Table 1. Strategic Risk Early Warning Criteria and Sub-Criteria

\begin{tabular}{|c|c|}
\hline Criteria & Sub - criteria \\
\hline Impact of strategic decisions & $\begin{array}{l}\text { change in interest rate } \\
\text { equity non availability } \\
\text { increase in inflation rate }\end{array}$ \\
\hline Competition position & $\begin{array}{l}\text { competitor's actions } \\
\text { depositor's behavior } \\
\text { regulatory change } \\
\text { new entries }\end{array}$ \\
\hline $\begin{array}{l}\text { Effectiveness of the Strategic Risk Management } \\
\text { Process }\end{array}$ & $\begin{array}{l}\text { Strategic planning process } \\
\text { Alignment and change management } \\
\text { Implementation and monitoring } \\
\text { Performance evaluation and feedback }\end{array}$ \\
\hline $\begin{array}{l}\text { Adequacy and Effectiveness of Strategic Risk } \\
\text { Management Structure }\end{array}$ & $\begin{array}{l}\text { Resistance to cultural change } \\
\text { Business development } \\
\text { Strategic risk management structure } \\
\text { Effectiveness of strategic risk management structure } \\
\text { The frequency and extent of the deviation between the written documentation } \\
\text { with the actual practice }\end{array}$ \\
\hline $\begin{array}{l}\text { Impact of Implementation } \\
\text { Strategies and Adequacy of } \\
\text { resources in carrying strategic decisions }\end{array}$ & $\begin{array}{l}\text { Allocation of adequate financial resources to support the strategic decisions } \\
\text { Board awareness } \\
\text { Human resources ( skills and qualifications) } \\
\text { Information systems infrastructure }\end{array}$ \\
\hline $\begin{array}{l}\text { Level of responsiveness Strategy against bank } \\
\text { business environment changes }\end{array}$ & $\begin{array}{l}\text { Technological progress } \\
\text { Political risk } \\
\text { Change in client behavior } \\
\text { Change in shareholder behavior } \\
\text { Change in employee behavior }\end{array}$ \\
\hline $\begin{array}{l}\text { Strategic objective conformance with strategic } \\
\text { goals, Internal and External Environmental } \\
\text { Conditions Business }\end{array}$ & $\begin{array}{l}\text { strategic planning } \\
\text { decision making method } \\
\text { market positioning } \\
\text { Organizational culture } \\
\text { Level of risk tolerance } \\
\text { Vision, mission and direction of the bank's business }\end{array}$ \\
\hline
\end{tabular}

Overall, our methodology process is set as follow:

1) Breaking down the complex strategic risk management problem into hierarchical structure into the following elements:

a) Overall goals to be attained

b) Criteria and sub-criteria,

c) Alternatives.

2) The models was constructed by defining the goal and structuring a non-linear criteria/alternatives

3) The decision was decomposed into factors (criteria) and sub-factors

4) Each level of the model reflected a redefinition of problem elements with increasing specificity

5) The models lead through a series of judgments on the factors and sub-factors

6) The judgment process was generally based on the relative significance or preference and likelihood of the criteria

7) Judgments was made utilizing the pair wise comparison method whereby individual decision factors are compared as isolated elements related to a common parent

8) Judgments was made verbally and numerically

9) The Super-Decision software , derived Ratio Scale Priorities by calculating the principle right eigenvector of the reciprocal matrix of pair wise judgments and excel is used to calculate the risk index of the main criteria

10) From multiple pair wise rating and comparisons, the researcher's experience and intuition are synthesized with objective data to yield effective strategic risk management at a early stage.

11) Inconsistency Ratio Analysis enables the researcher to test the mathematical accuracy of judgments within the model to identify and correct errors in entering judgments, lack of concentration and inappropriate use of extremes 
The first step in this AHP analytical process is to present a pictorial representation of our AHP model as shown in Fig.1. The first level of our model is our goal which is to rank those threats (risk factors) according to their risk index in order to provide an early soundness of the bank stability at a strategic level. At the second level, our AHP model distinguished, 'Importance' and 'Likelihood' which stand for the significance of the factors of harming an institution at the strategic level, and the likelihood of occurrence of these factors. This indicates that we will set the Risk index of the 7 main strategic risk factors set out at Level 3 in terms of their relative 'Importance or significance' and the 'Likelihood' that they will occur in a certain situation. Level 4 is the rating scale which is used to evaluate each risk under the appropriate basic strategic risk factor.

ranking the criteria and sub-criteria in terms of significance and likelihood reveal a great significance in so far that the final result is obtain by amalgamating the two priorities result to provide a risk index of the strategic risk. This we can do with a 'product model' derived by multiplying the respective pair-wise values for Significance and Likelihood which results in risk index priorities. This result can be interpreted as " how likely and at which level a factor can cause strategic risk within a bank".

In order to rate the different sub-factors, a rating scale with the following categories was developed. A verbal statement of preferences ${ }^{\text {ee }}$ was created and rating values ${ }^{e e}$ was assigned as 8, 6, 4 and 2 as it shows in table 2 below. A verbal statement of preferences was filled out in rating model and the rating values were used in Pair-wise Questionnaire comparisons to evaluate the risk categories intensity as it shows in table 3.

Table 2. Rating Scale For Evaluating Strategic Risk Factors

\begin{tabular}{|l|l|l|}
\hline Category & value & definition \\
\hline High risk level & 8 & Identifies as high risk \\
\hline Moderate risk level & 6 & Identified as moderate risk \\
\hline Low risk level & 4 & Identified as low risk \\
\hline Basic risk level & 2 & Identified as basic risk \\
\hline
\end{tabular}

Table 3. Risk Categories Weight

\begin{tabular}{|l|l|l|}
\hline Category & intensity & Re-scaled weight \\
\hline High risk level & 0.52 & 1 \\
\hline Moderate risk level & 0.26 & 0.5 \\
\hline Low risk level & 0.15 & 0.3 \\
\hline Basic risk level & 0.05 & 0.1 \\
\hline
\end{tabular}

After established the priorities for the main factors (criteria), we developed priorities for the specific 'threats or sub- criteria using the rating scale we have established. In the case of each threat', we establish its priority via a rating scale and assign it the commensurate result. For example, the threat 'change in interest rate' is identified as a 'high' risk and gets the highest rating possible. We go through the same process for all the subcriteria 'threats' so that each is identified as being a 'high' risk, a 'Moderate' risk, a 'Low' risk or a 'Basic' risk. To get the final weights for all threat or sub-criteria originally listed, the ratings are moderated by the 'main criteria priorities' established for Strategic risk factors given above (seven in total).

A verbal statement of preferences was filled out in rating model and the rating values were used in Pair-wise Questionnaire comparisons to determine the specific criteria and sub-criteria priorities and risk proficiency. The assigning of categories from High, Moderate, Low and Basic, with respect to the Strategic risk components were performed with help of expert opinion and the review of the literature. To get the final weights for all threat alternatives originally listed, the threat ratings are moderated by the 'criteria priorities' established for the strategic risk factors given above. 


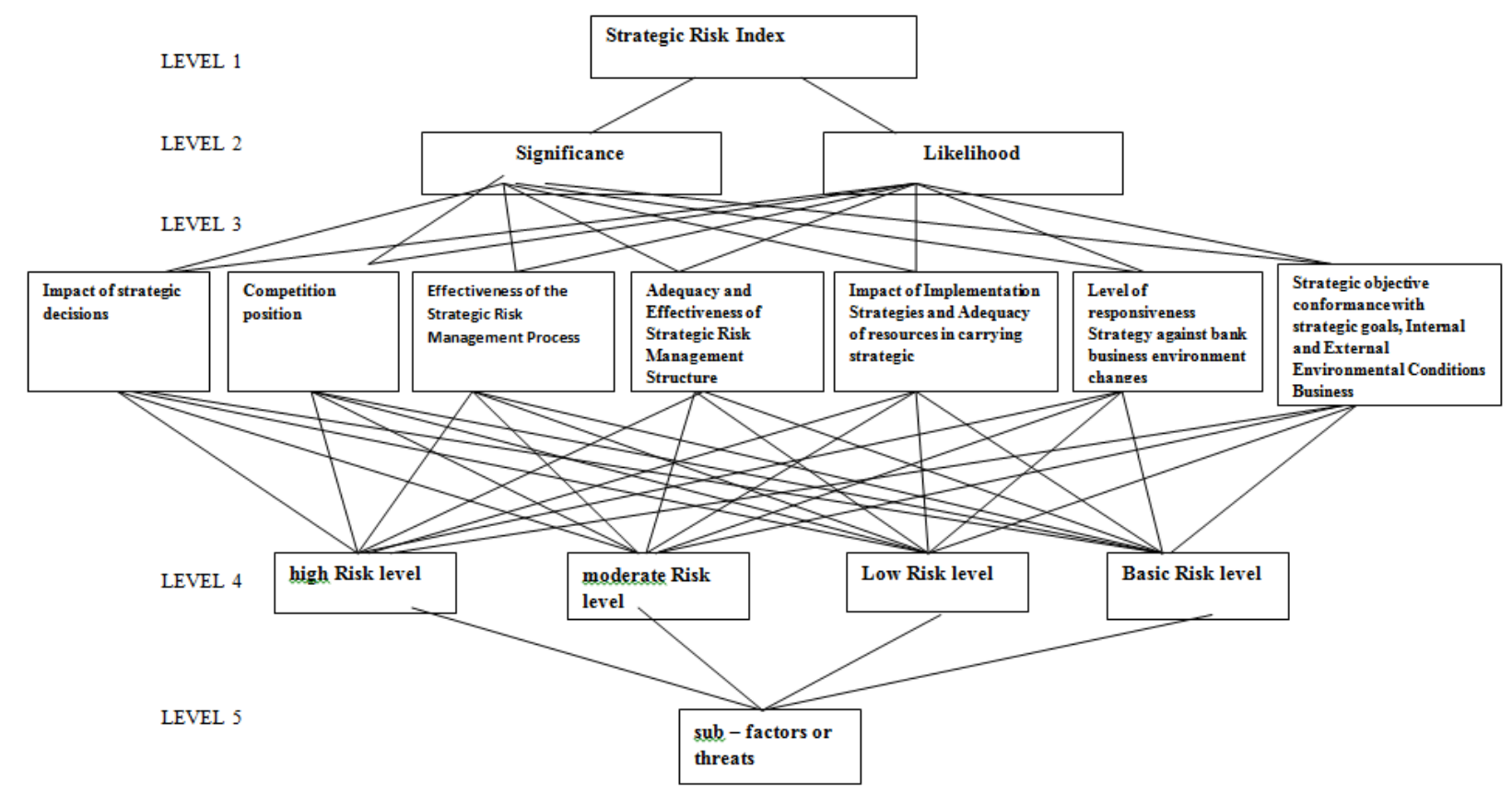

Figure 1. Analytical Hierarchy Process Strategic Risk Model

\section{Results and Discussion}

The decision problem structure allows us to establish the weighting for each one of the strategic risk factors used as criteria and sub-criteria. The goal of this process being to identify and assess how significant and important these factors are regarding the occurrence of strategic risk within a bank, the results are relevant and totally in accordance with the theoretical framework about strategic risk management. The weightings for each factor are shown in Table 4 It can be seen that it terms of relative importance of factors characterizing strategic risk, the weightings of the main seven (7) factors fluctuated between 4 and $40 \%$, showing a slight imbalance between them. This implies that the importance assigned to each risk factor was quite not similar in terms of importance in the earlier detection of strategic distress in banks. the weighting obtained can be interpreted as the percentage that each factor influences the total risk perception of the bank's activity. In this case, it can be said that the most relevant risk factor or strategic risk component the board have to focus on is the "Effectiveness of the Strategic Risk Management Process" that represented 39\% of the total strategic risk perception, while the " competitor's position" showed the lowest risk with 4\%. The "Adequacy and Effectiveness of Strategic Risk Management Structure" with a weight of $20 \%$, is perceived as the second risk factor that the board should consider at the earlier stage of the strategic risk assessment, while keeping a great attention to the "Strategic objective conformance with strategic goals, Internal and External Environmental Conditions Business" factor which rank third according to the results. The results regarding the importance and significance of the risk factors also pointed out as we can see $\mathrm{n}$ the table above, that the bank's executives should keep an eye on the "Level of responsiveness Strategy against bank business environment changes" which is reveal to be also of a great significance in the earlier assessment of strategic risk distress signs with $12 \%$ weight. The "impact of strategic decisions" and the "Impact of Implementation Strategies and Adequacy of resources in carrying strategic decisions" respectively with $6 \%$ and $5 \%$ are not to be left apart considering their relative importance and the correlation with the other factors.

Assessing the main strategic risk factors in terms of significance and importance provide relevant information to the bank's board and executives on how those factors have to be prioritized and considered in term of the impact they have regarding the occurrence of risk at the strategic level. But ranking the factors only with respect to their importance is not sufficient to define an early warning index for strategic risk, they have to be also assessed in terms of the expectation of likelihood and the combination of the two results will provide a risk weight index for strategic risk assessment. The obtained results are shown in table 5.

As it can be seen in table 5, the ordering of weights for the seven main factors characterizing strategic risk in banks has changed. What is tried to be depicted here is to rank the factors in terms of expected risk or the probability that a given factor harm or cause a risk at the strategic level. When proceeding that way, the structure is quite different than ranking only for importance. The result suggested that "Strategic objective conformance with strategic goals, Internal and External Environmental Conditions Business" with 32\%, is likely to arise as a risk or expected to cause more damage at a strategic level. it means that when the strategic objectives of the bank is not in conformance with strategic goals and the external environment conditions, there 
is a high probability ( $32 \%$ according to the experts) that this situation lead to a strategic risk. The "Level of responsiveness Strategy against bank business environment changes" which rank at the fourth place in terms of importance, is view by the expert to be likely risk oriented. from this point of view, the results clearly stated that the strategy planned by the board has to be responsive and adapted to the changes in the banking environment otherwise it can result in a strategic risk with $26 \%$ of chances ( according to the results). the 'Effectiveness of the Strategic Risk Management Process" now ranked at the third place in terms of expected risk and is at $12 \%$ of chances likely of harming the institution's business at the strategic level, hence an effective and adequate risk management process have to be implemented for the earlier assessment of any strategic vulnerability. Further, the results show that the "Impact of Implementation Strategies and Adequacy of resources in carrying strategic decisions" with a total weight of $11 \%$ is likely to be a great source of strategic risk if not taken into consideration. in terms of expected risk, The "Adequacy and Effectiveness of Strategic Risk Management Structure", the " competitor's position" and the "impact of strategic decisions" are perceived respectively as the fifth, the sixth and the seventh likely risk exposure. the information provided in this context reflect the fact that a lack of a strategic risk management structure within a bank will at $10 \%$ probably have an impact or be a cause of a strategic risk as it will be for the competitor's position ( $4 \%$ ) and the impact of the strategic decision taken by the board $(2 \%)$.

\begin{tabular}{|c|c|c|}
\hline Name & Weights & Limiting \\
\hline 1 ISD & 0.06065 & 0.020218 \\
\hline $2 \mathrm{CP}$ & 0.03911 & 0.013038 \\
\hline 3 ESRMP & 0.39726 & 0.13242 \\
\hline 4 AESRMS & 0.1994 & 0.066465 \\
\hline 5 IISARCS & 0.04764 & 0.01588 \\
\hline 6 LRSBBEC & 0.11527 & 0.038424 \\
\hline 7 SOCSGIEE & 0.14066 & 0.046887 \\
\hline 1 change in interest rate & 0.1884 & 0.003809 \\
\hline 2 equity non availability & 0.73064 & 0.014772 \\
\hline 3 increase in inflation rate & 0.08097 & 0.001637 \\
\hline 1 competitor's actions & 0.06734 & 0.000878 \\
\hline 2 depositor's behavior & 0.41647 & 0.00543 \\
\hline 3 regulatory change & 0.13323 & 0.001737 \\
\hline 4 new entries & 0.38296 & 0.004993 \\
\hline 1 Strategic planning process & 0.55558 & 0.07357 \\
\hline 2 Alignment and change management & 0.24876 & 0.032941 \\
\hline 3 Implementation and monitoring & 0.11468 & 0.015186 \\
\hline 4 Performance evaluation and feedback & 0.08098 & 0.010723 \\
\hline 1 Resistance to cultural change & 0.279 & 0.018544 \\
\hline 2 Business development & 0.03712 & 0.002467 \\
\hline 3 Strategic risk management structure & 0.1483 & 0.009857 \\
\hline 4 Effectiveness of strategic risk management structure & 0.46924 & 0.031188 \\
\hline 5 The frequency and extent of the deviation & 0.06634 & 0.004409 \\
\hline 1 Allocation of adequate financial resources to support the strategic decisions & 0.15851 & 0.002517 \\
\hline 2 Board awareness & 0.46558 & 0.007393 \\
\hline 3 Human resources ( skills and qualifications) & 0.32955 & 0.005233 \\
\hline 4 Information systems infrastructure & 0.04635 & 0.000736 \\
\hline 1 Technological progress & 0.0546 & 0.002098 \\
\hline 2 Political risk & 0.12513 & 0.004808 \\
\hline 3 Change in client behavior & 0.21085 & 0.008102 \\
\hline 4 Change in shareholder behavior & 0.38608 & 0.014835 \\
\hline 5 Change in employee behavior & 0.22334 & 0.008582 \\
\hline 1 strategic planning & 0.11419 & 0.005354 \\
\hline 2 decision making method & 0.04074 & 0.00191 \\
\hline 3 market positioning & 0.05138 & 0.002409 \\
\hline
\end{tabular}


4 Organizational culture

5 Level of risk tolerance

6 Vision, mission and direction of the bank's business

\subsection{7}

0.1761

0.13852

Table 5. Likelihood Priorities

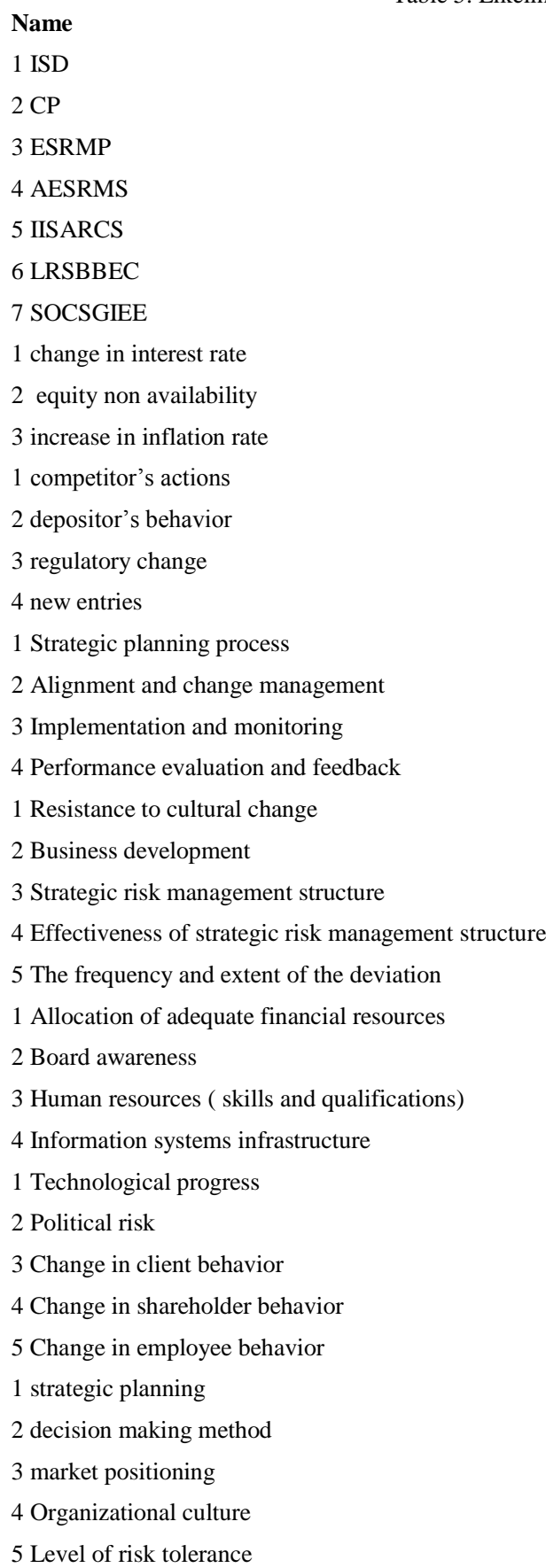

Weight

$$
0.02369
$$

0.04407

0.12806

0.10547

0.11251

0.26217

0.32403

0.19998

0.19998

0.60003

0.41136

0.41136

0.06413

0.11314

0.5827

0.12895

0.15995

0.12839

0.26054

0.04092

0.30857

0.30857

0.08139

0.29104

0.17372

0.47366

0.06158

0.03366

0.15621

0.16911

0.06902

0.08121

0.29788

0.03474

0.29681

0.11638
0.57201
0.022462

0.008257

0.006495

Limiting

0.011846

0.022035

0.064031

0.052733

0.056255

0.131084

0.162015

0.002369

0.002369

0.007108

0.009064

0.009064

0.001413

0.002493

0.037311

0.008257

0.010242

0.008221

0.013739

0.002158

0.016272

0.016272

0.004292

0.016373

0.009773

0.026646

0.003464

0.004412

0.074981

0.020476

0.022167

0.009048

0.013158

0.048262

0.005628

0.048088

0.018856 
Table 6. Strategic Risk Index

\begin{tabular}{|c|c|c|c|}
\hline Name & SIGNIFICANCE & LIKELIHOOD & RISK INDEX \\
\hline 1 Strategic planning process & 0.55558 & 0.5827 & 0.32373647 \\
\hline 2 depositor's behavior & 0.41647 & 0.41136 & 0.1713191 \\
\hline 3 Human resources ( skills and qualifications) & 0.32955 & 0.47366 & 0.15609465 \\
\hline 2 equity non availability & 0.73064 & 0.19998 & 0.14611339 \\
\hline 4 Effectiveness of strategic risk management structure & 0.46924 & 0.30857 & 0.14479339 \\
\hline 4 Organizational culture & 0.47907 & 0.29681 & 0.14219277 \\
\hline 2 Board awareness & 0.46558 & 0.17372 & 0.08088056 \\
\hline 1 Resistance to cultural change & 0.279 & 0.26054 & 0.07269066 \\
\hline 2 Political risk & 0.12513 & 0.57201 & 0.07157561 \\
\hline 4 Change in shareholder behavior & 0.38608 & 0.16911 & 0.06528999 \\
\hline 3 ESRMP & 0.39726 & 0.12806 & 0.05087312 \\
\hline 3 increase in inflation rate & 0.08097 & 0.60003 & 0.04858443 \\
\hline 1 Allocation of adequate financial resources & 0.15851 & 0.29104 & 0.04613275 \\
\hline 3 Strategic risk management structure & 0.1483 & 0.30857 & 0.04576093 \\
\hline 7 SOCSGIEE & 0.14066 & 0.32403 & 0.04557806 \\
\hline 4 new entries & 0.38296 & 0.11314 & 0.04332809 \\
\hline 1 change in interest rate & 0.1884 & 0.19998 & 0.03767623 \\
\hline 3 Change in client behavior & 0.21085 & 0.15621 & 0.03293688 \\
\hline 2 Alignment and change management & 0.24876 & 0.12895 & 0.0320776 \\
\hline 6 LRSBBEC & 0.11527 & 0.26217 & 0.03022034 \\
\hline 1 competitor's actions & 0.06734 & 0.41136 & 0.02770098 \\
\hline 6 Vision, mission and direction of the bank's business & 0.13852 & 0.17297 & 0.0239598 \\
\hline 4 AESRMS & 0.1994 & 0.10547 & 0.02103072 \\
\hline 5 Level of risk tolerance & 0.1761 & 0.11638 & 0.02049452 \\
\hline 3 Implementation and monitoring & 0.11468 & 0.15995 & 0.01834307 \\
\hline 5 Change in employee behavior & 0.22334 & 0.06902 & 0.01541493 \\
\hline 2 decision making method & 0.04074 & 0.29788 & 0.01213563 \\
\hline 4 Performance evaluation and feedback & 0.08098 & 0.12839 & 0.01039702 \\
\hline 1 strategic planning & 0.11419 & 0.08121 & 0.00927337 \\
\hline 3 regulatory change & 0.13323 & 0.06413 & 0.00854404 \\
\hline 5 The frequency and extent of the deviation & 0.06634 & 0.08139 & 0.00539941 \\
\hline 5 IISARCS & 0.04764 & 0.11251 & 0.00535998 \\
\hline 4 Information systems infrastructure & 0.04635 & 0.06158 & 0.00285423 \\
\hline 1 Technological progress & 0.0546 & 0.03366 & 0.00183784 \\
\hline 3 market positioning & 0.05138 & 0.03474 & 0.00178494 \\
\hline $2 \mathbf{C P}$ & 0.03911 & 0.04407 & 0.00172358 \\
\hline 2 Business development & 0.03712 & 0.04092 & 0.00151895 \\
\hline 1 ISD & 0.06065 & 0.02369 & 0.0014368 \\
\hline
\end{tabular}

Having established our model based on the significance and the expectation of likelihood for the main factors, we ultimately have all the elements to set a risk index (as it shows in table 6 above) on which the board and executives should definitively focus while assessing strategic risk. This index shows how much importance and consideration should be given to each factor while managing strategic risk. It also shows the probability that any of these factors could cause a strategic risk if not taken care of, or failed to be implemented. It finally provides a signal and soundness on whether strategic risk is contained within the risk appetite and the risk profile set by the bank. the risk index also give a relevant information on how efficiently strategic risk is managed within a bank and which risk level the institution can be exposed if the board failed to comply with the model.

establishing the strategic risk index by amalgamating the priorities of significance and the expectation of likelihood, provide a useful information to the bank's board and executives for the earlier detection of any soundness or vulnerabilities at the strategic level. relying on the above results, it is obvious that the three main 
factors on which the board should focus at first in their process of strategic risk assessment and which provide the most strongest signal of a strategic deterioration of the banking business are definitively the "Effectiveness of the Strategic Risk Management Process", the "Strategic objective conformance with strategic goals, Internal and External Environmental Conditions Business" and the "Level of responsiveness Strategy against bank business environment changes". putting the emphasis on these three main factors in priority ensure the institution to stay in line with its strategic objectives, and to get early signals in case of any vulnerabilities or risk that may harm the bank's activities at the strategic level.

The model while assessing in details the specific factors that may provide signals of strategic vulnerability reach conclusions that support the theoretical evidences about risk management at the strategic level and brought a deep understanding on how effectively board and the executives can perceive and analyze strategic deterioration signals in banks. The model provides, as it can be seen in table 7 and 8 , useful information about the specific factors characterizing strategic risk in banks and the corresponding signal that can be transmitted by each of them in terms of risk level

The results contained in the table 7 and 8 concern the rating evaluation process and show the rating priorities of each strategic risk factor as well as the risk level each of them belongs to. Relying on the obtained results, strategic planning process and the resistance to culture change within a bank are revealed to be the factors that provide the strongest signal of a strategic vulnerability and which may be given a certain consideration and focus by the board. the results further suggests that factors such as decision making method, organizational culture, strategic planning, change in shareholder's behavior, political risk and the level of risk tolerance, not to mention all, should be given a prior attention in order to be one foot ahead of any strategic concern. Thus far, we have produced a model results which rank and rate strategic risk factors and sub- factors in terms of combined values of importance and expectation of likelihood. We argue that this is a fundamental requirement in developing a strategic risk assessment at an earlier stage. We argue further that this hierarchy of priorities can be of great use in helping in the decision-making process by allowing the level and kind of resources committed (board and banks executives) to managing these threats to reflect systematically the prior evaluation of risk and take adequate measures to contain them within risk boundaries defined by the institutions.

Table 7. Rating scores

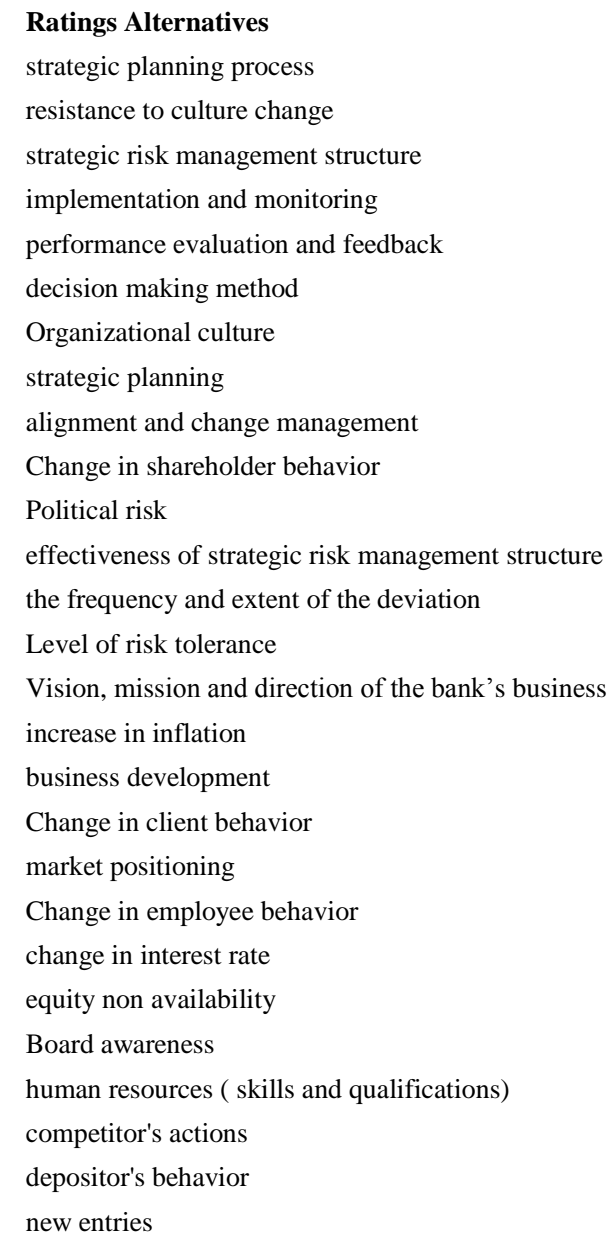

\begin{tabular}{|c|c|c|c|}
\hline Total & Ideal & Normal & Ranking \\
\hline 0.1986 & 1 & 0.1438 & 1 \\
\hline 0.0997 & 0.5019 & 0.0722 & 3 \\
\hline 0.0997 & 0.5019 & 0.0722 & 2 \\
\hline 0.0993 & 0.5 & 0.0719 & 5 \\
\hline 0.0993 & 0.5 & 0.0719 & 4 \\
\hline 0.0703 & 0.3541 & 0.0509 & 6 \\
\hline 0.0703 & 0.3541 & 0.0509 & 8 \\
\hline 0.0703 & 0.3541 & 0.0509 & 7 \\
\hline 0.0601 & 0.3024 & 0.0435 & 9 \\
\hline 0.0576 & 0.2902 & 0.0417 & 11 \\
\hline 0.0576 & 0.2902 & 0.0417 & 10 \\
\hline 0.0498 & 0.251 & 0.0361 & 13 \\
\hline 0.0498 & 0.251 & 0.0361 & 12 \\
\hline 0.0352 & 0.177 & 0.0255 & 15 \\
\hline 0.0352 & 0.177 & 0.0255 & 14 \\
\hline 0.0303 & 0.1527 & 0.022 & 16 \\
\hline 0.0301 & 0.1518 & 0.0218 & 17 \\
\hline 0.0288 & 0.1451 & 0.0209 & 18 \\
\hline 0.0213 & 0.1071 & 0.0154 & 19 \\
\hline 0.0174 & 0.0877 & 0.0126 & 20 \\
\hline 0.0152 & 0.0763 & 0.011 & 21 \\
\hline 0.0152 & 0.0763 & 0.011 & 22 \\
\hline 0.01 & 0.0501 & 0.0072 & 23 \\
\hline 0.01 & 0.0501 & 0.0072 & 24 \\
\hline 0.0098 & 0.0492 & 0.0071 & 25 \\
\hline 0.0098 & 0.0492 & 0.0071 & 27 \\
\hline 0.0098 & 0.0492 & 0.0071 & 26 \\
\hline
\end{tabular}


Technological progress

regulatory change

allocation of adequate financial resources

Information systems infrastructure

$\begin{array}{llll}0.0061 & 0.0309 & 0.0044 & 28 \\ 0.0059 & 0.0298 & 0.0043 & 29 \\ 0.0043 & 0.0216 & 0.0031 & 30 \\ 0.0043 & 0.0216 & 0.0031 & 31\end{array}$

Table 8. Strategic Risk Factors Weighted Index

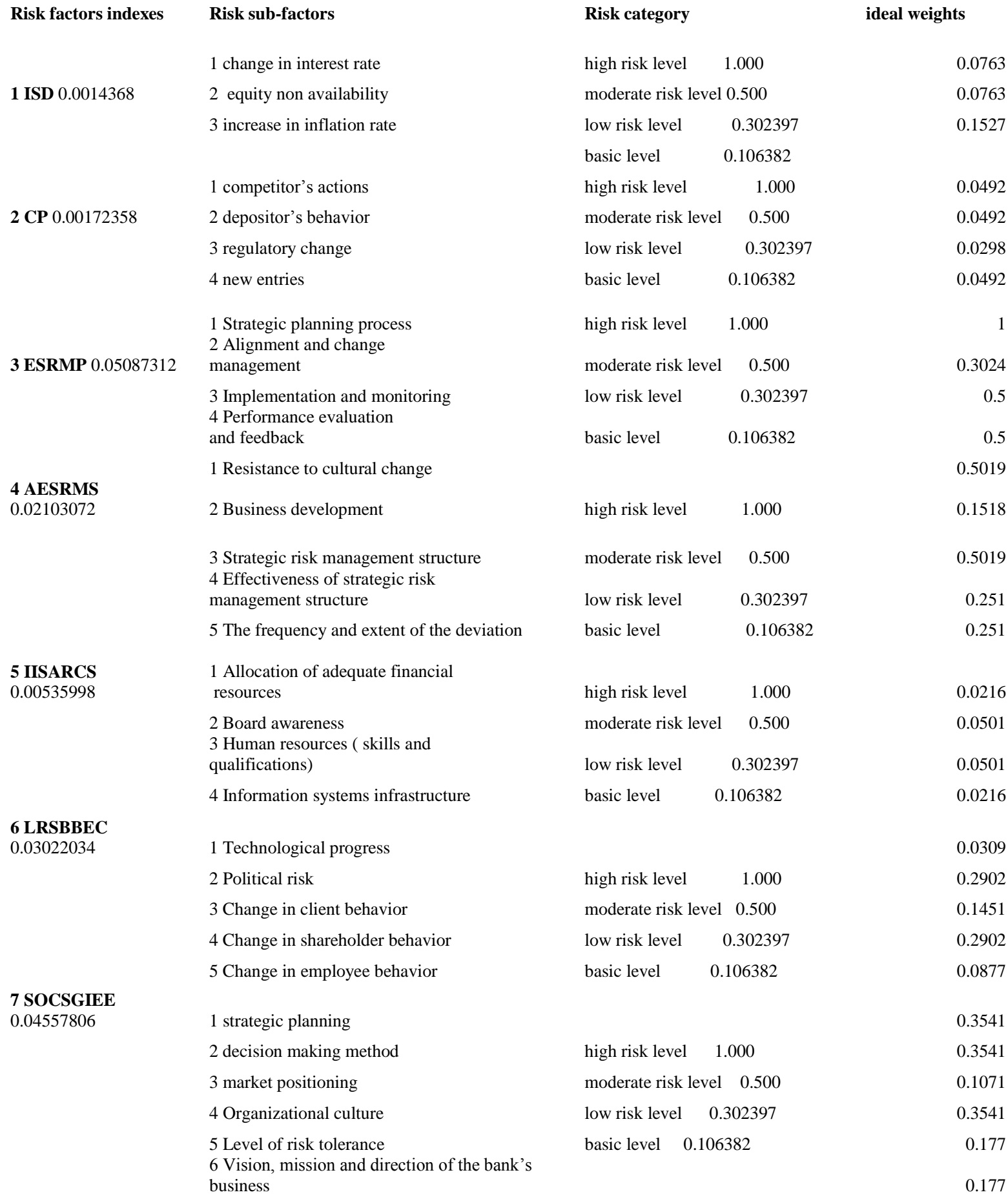




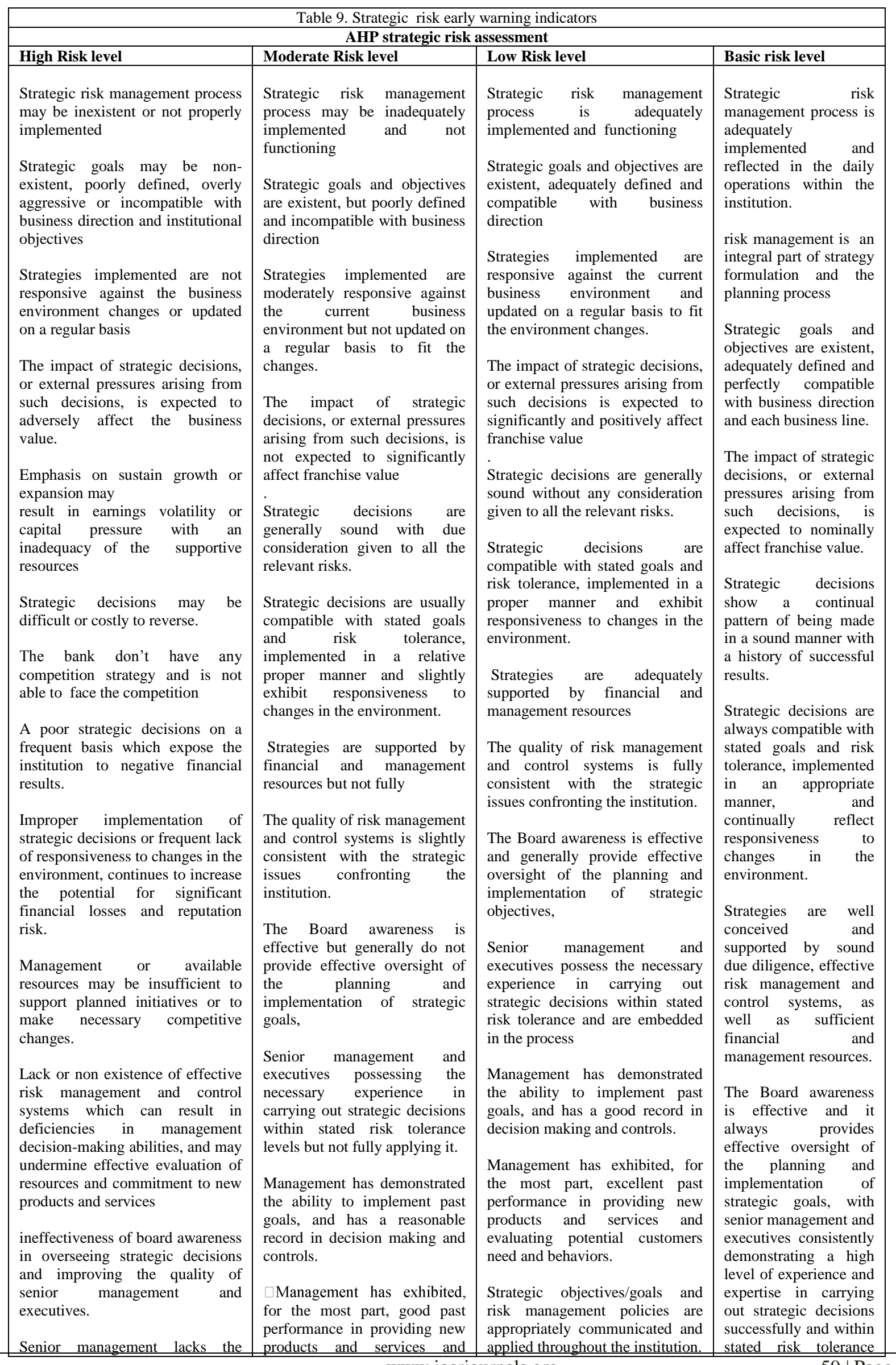




\begin{tabular}{|c|c|c|c|}
\hline $\begin{array}{l}\text { necessary experience or skills and } \\
\text { qualifications to effectively direct } \\
\text { the communication, } \\
\text { implementation and modification } \\
\text { of strategic plans and maintain } \\
\text { consistency with stated risk } \\
\text { tolerance levels. } \\
\text { Management has a track record of } \\
\text { poor past } \\
\text { performance in offering new } \\
\text { products and services } \\
\text { and evaluating potential customers } \\
\text { need, behaviors } \\
\text { Strategic objectives/goals and risk } \\
\text { management policies may not be } \\
\text { clearly communicated and } \\
\text { consistently applied throughout the } \\
\text { institution } \\
\text { Corporate structure and culture are } \\
\text { not suitable or adequate to enhance } \\
\text { risk management and may be } \\
\text { insufficient to support strategic } \\
\text { direction or address a changing } \\
\text { environment }\end{array}$ & $\begin{array}{l}\text { evaluating potential customers } \\
\text { need and behaviors. } \\
\text { Strategic objectives/goals and } \\
\text { risk management policies are } \\
\text { communicated and sometimes } \\
\text { applied throughout the } \\
\text { institution. } \\
\text { Corporate structure and culture } \\
\text { are moderately suitable or } \\
\text { adequate to enhance risk } \\
\text { management but may be } \\
\text { insufficient to support strategic } \\
\text { direction or address a changing } \\
\text { environment benchmark } \\
\text { The bank } \\
\text { competitor's actions but does } \\
\text { not have enough resources to } \\
\text { face the competition. }\end{array}$ & $\begin{array}{l}\text { Corporate structure and culture } \\
\text { are suitable and adequate to } \\
\text { enhance risk management, and is } \\
\text { adapted to support strategic } \\
\text { direction or address a changing } \\
\text { environment } \\
\text { The bank benchmark } \\
\text { competitor's actions and set the } \\
\text { appropriate strategies to face the } \\
\text { competition with adequate } \\
\text { resources. }\end{array}$ & $\begin{array}{l}\text { levels. } \\
\text { Management has been } \\
\text { successful in } \\
\text { accomplishing past } \\
\text { goals, with a history of } \\
\text { excellent performance } \\
\text { in providing new } \\
\text { products and services } \\
\text { and evaluating } \\
\text { potential customers } \\
\text { needs and behaviors. } \\
\text { Strategic direction and } \\
\text { organizational } \\
\text { efficiency are enhanced } \\
\text { by the depth of the } \\
\text { human resource skills } \\
\text { and qualifications as } \\
\text { well as the executives } \\
\text { oversight. } \\
\text { Strategic goals and risk } \\
\text { management policies } \\
\text { are effectively } \\
\text { communicated and } \\
\text { consistently applied } \\
\text { throughout an the } \\
\text { institution. } \\
\text { Corporate structure is } \\
\text { adapted to risk } \\
\text { management process } \\
\text { and the organizational } \\
\text { culture effectively } \\
\text { supports strategic } \\
\text { direction and } \\
\text { initiatives. }\end{array}$ \\
\hline
\end{tabular}

The analysis of the results provided by the AHP assessment led to the establishment of a strategic risk map in terms of early indicators of vulnerabilities based on the main factors defined earlier. This map provides signals in terms of risk level and is revealed to be of great importance for banking executives and boards in their process of risk management at the strategic level as it help to take the appropriate measures in case that any of the situations described in the model happen. Table 9 gives a summary of the proposed early indicators. the model provides signals ranging from basic risk level to high risk level according to how efficiently the different strategic risk factors are managed and perceived, with regards to the significance and the expectation of likelihood of each of them. Consequently, based on our model, a bank which is exposed to a high risk level can definitively get signals depicting the inexistent or an improperly implemented Strategic risk management process coupled with the strategic goals which may be non-existent, poorly defined, aggressive or incompatible with business direction and institutional objectives. Strategies implemented may be not responsive against the business environment changes or updated on a regular basis and the impact of the strategic decisions, or external pressures arising from such decisions, is expected to adversely affect the business value. in addition, the emphasis on sustain growth or expansion may result in earnings volatility or capital pressure with an inadequacy of the supportive resources and strategic decisions may be difficult or costly to reverse. Furthermore, the bank won't have any competition strategy and won't be able to face the competition. it will rely on poor strategic decisions on a frequent basis which will expose the institution to negative financial results, and the improper implementation of strategic decisions or frequent lack of responsiveness to changes in the environment will continue to increase the potential for significant financial losses and reputation risk. a bank that has a high probability to be exposed to strategic risk may see it Management or available resources insufficient to support planned initiatives or to make necessary competitive changes. it organizational structure will be characterized by a lack or non existence of effective risk management and control systems which can result in deficiencies in management decision-making abilities, and may undermine effective evaluation of resources and commitment to new products and services. In addition, the ineffectiveness of board awareness in overseeing strategic decisions and improving the quality of senior management and executives will be remarkable and obviously strategic objectives/goals and risk management policies may not be clearly communicated and consistently applied throughout the institution. 
These aspects constitute a light for the banking institutions and represent a signal for the earlier identification of a bank which is exposed to a high strategic risk. the level of the risk to be exposed to, is expecting to change favorably to a basic risk exposure throughout the improvement of the management quality and the risk assessment within the bank as it can be seen in table 9.

\section{Conclusion}

This study intends to design an early warning system of strategic risk based on the AHP model and the relative weight of the main indicators of strategic risk in banks. The purpose was specifically to analyze how Togolese commercial banks generally assess strategic risk and to design a set of warning signal scale range from high to low level of risk.

The study brought remarkable information on how strategic vulnerabilities or distress can be detected and assess by providing in the one hand some risk factors on which bank's board should necessarily focus on and pay attention for the well being of their business, and in the other hand, some earlier signals of strategic deterioration with respect to the level of risk likely to harm the institution. Accordingly, our conclusions on this particular aspect suggest that in terms of the combined significance and likelihood of expectation of strategic risk factors, board should primarily focus on the three main factors which provide the most strongest signal of a strategic deterioration of the banking business namely the 'Effectiveness of the Strategic Risk Management Process", the "Strategic objective conformance with strategic goals, Internal and External Environmental Conditions Business" and the "Level of responsiveness Strategy against bank business environment changes". putting the emphasis on these three main factors in priority ensure the institution to stay in line with its strategic objectives, and to get early signals in case of any vulnerabilities or risk that may harm the bank's activities at the strategic level. more specifically, strategic planning process and the resistance to culture change within a bank are revealed to be the factors that provide the strongest signal of a strategic vulnerability and which may be given a certain consideration and focus by the board, with a particular attention given to factors such as the decision making method, organizational culture, strategic planning, change in shareholder's behavior, political risk and the level of risk tolerance.

The study further established that risk management practices and especially strategic risk management remain a relatively new approach which is not yet a part of the organizational culture of most of the commercial banks in Togo. The overall knowledge on strategic risk and all the aspect surrounding its management process has been proven by this study to be literally weak within the banking sector.. It shows that the risk management culture is a key factor to establishing a strategic risk management framework and that structural and behavioral changes as well as strengthening organizational culture towards risk are needed within banks to enhance an appropriate strategic risk management process. The research finally established as we can see in table 9, a map of the qualitative early signals based on the risk level likely to arise regarding the assessment of the main indicators characterizing strategic risk in banks, and concludes that within Togolese banks, risk management is not yet an integral part of strategy formulation and building a risk focus culture remain the challenge.

\section{References}

[1] Audrey Mahuet, Thomas Lambert and Jacques Le Cacheux, L'épidémie de crises bancaires dans les pays de l'OCDE, Revue de l'OFCE no 61/ avril (1997), 93- 168

[2] Rebel A. Cole and Jeery W. Gunther, A CAMEL Rating's Shelf Life, DePaul University, Federal Reserve Bank, MPRA Paper No. 24693, november 1995

[3] Sahajwala R. and Van Den Bergh "Supervisory Risk Assessment And Early Warning Systems", Working Paper N4, Basel Committee On Banking Supervision, 2000

[4] Basel Committee On Banking Supervision [2004], International Convergence Of Capital Measurement And Capital Standards, A Revised Framework. Bank for International Settlements Press \& Communications Ch-4002 Basel, Switzerland

[5] Gaytán, Alejandro; Johnson, Christian A. (2002), A Review of the Literature on Early Warning Systems for Bank-ing Crises, Central Bank of Chile Working Paper, No. 183, Santiago, October 2002.

[6] James B. Thomson, 1991. "Predicting bank failures in the 1980s," Economic Review, Federal Reserve Bank of Cleveland, issue Q I, pages $9-20$

[7] Arturo Estrella, Sangkyun Park and Stavros Peristiani, Capital Ratios as Predictors of Bank Failure, Economic Policy Review, Vol. 6, No. 2, July 2000

[8] Amran, A., Bin, A.M.R. and Hassan, B.C.H.M., (2009). 'Risk Reporting: An Exploratory Study on Risk Management Disclosure in Malaysian Annual Reports'. Managerial Auditing Journal , 24 (No.1):39-57.

[9] Hassan, M.K., (2009). 'UAE corporations specific characteristics and level of risk disclosure'. Managerial Auditing Journal , 24 (7):668 -687

[10] Al-Tamimi, H. and Al-Mazrooei M., 2007, "Banks' Risk Management: A Comparison Study of UAE National and Foreign Banks", The Journal of Risk Finance, Vol. 8 No.4, pp. 394-409

[11] Li Peng, Study on Bank Reputation Risk Early-warning System and Enmergency Response Mechanism Construction. E -Business and E-Government (ICEE), 2011 International conference. p 1-3, May 2011

[12] Demirguc-Kunt Ash "Modeling Large Commercial-Bank Failures A Simultaneous Equation Analysis, Federal Reserve Bank of Cleveland Working Paper 8905 May 1989a 